\title{
A STUDY OF PRESSURE AND TEMPERATURE EFFECTS
} IN EARTH-CURRENT MEASUREMENTS.

\author{
By S. J MaUchly.*
}

\section{INTRODUCTION.}

A large portion of the earth-current data now available is based upon observations made on commercial telegraph lines. During times of abnormal activity, the horizontal potentialgradient frequently assumes values of the order of 0.5 volt per kilometer, and sometimes exceeds ten times this value. For earthcurrent measurements made during such periods and also for extended series of measurements made on lines of great length, the difference of potential between the terminals is so great that most of the variations due to local causes at the earth-plates may safely be assumed to play only a minor part in the production of the observed phenomena.

However, partly because of the fact that commercial lines can, at best, be available only part of the time for scientific observations, and partly because of the desirability of controlling such matters as the location of lines, nature of earth-plates, etc, it is preferable, wherever possible, to install special lines for earth-current measurements. Geological conditions, as well as financial and other considerations, usually make it necessary or at least desirable to limit the length of such special lines. When this is done we are no longer justified in making the assumption referred to above, and it becomes desirable to investigate the relation between the total variations observed and those due to local causes. The general nature of the various components of the current measured on short lines has been well set forth by $\mathrm{Chree}^{1}$ and by Nippoldt. ${ }^{2}$ The experiments to be described were carried out with a view of determining more definitely the nature and order of magnitude of some of these spurious effects.

It is well known that variations in the moisture and temperature of the soil in contact with the plate terminals of an earth-current line produce corresponding variations in the E. M. F. of the pri-

\footnotetext{
* Report on special earth-current investigations made at the laboratory of the Department of Terrestrial Magnetism at Washington, 1916-1917, preparatory to the inauguration of earthcurrent observations at the observatories to be established by the Department. A paper on the subject was presented before the Philosophical Society of Washington, April 13, 1918
} 
mary cell consisting of the two earth-plates and the intervening soil. To eliminate effects due to both these causes, the plates are usually buried at a considerable depth, so that the conditions may be assumed fairly constant, at least so far as the diurnal variation is concerned. But when the lines connect points at considerable difference of elevation this procedure obviously cannot eliminate the effect just mentioned unless the plates are buried much deeper than is customary.

Attention has several times been directed to relatively large currents between plates buried at different depths. ${ }^{3}$ Since the general existence of a vertical earth-current density of an order of magnitude much larger than the atmospheric-electric current density seems inconsistent with the principle of continuity of flow of electricity, it seemed desirable to attack first the problem of determining whether much of the so-called vertical-current density was not a phenomenon which owed its origin to spurious causes, such, for example, as those arising from differential pressureeffects and temperature effects at the electrodes. The first part of the paper is devoted to the results of laboratory experiments dealing mainly with a pressure effect, while the second part is based on out-of-door measurements dealing with temperature effects.

\section{Part I - Laboratory Experiments Relating to the Electro- motive Force Associated with a Difference in Pressure Between Two Earth-Plates.}

A glass tube $150 \mathrm{~cm}$. long and $5 \mathrm{~cm}$. internal diameter was filled with freshly-dug, rather sandy, soil of uniform composition, and one of two similar (amalgamated zinc) electrodes imbedded in the soil near each end, the tube being vertical. As is to be expected, when these electrodes are connected to a sensitive galvanometer, a current is indicated; but if any portion of the E. M. F. owes its origin to pressure-difference at the two electrodes, this portion may be expected to reverse its direction relative to the tube when the tube is inverted, similar to the effect observed in salt solutions by Des Coudres ${ }^{4}$ and others. With a tube of smooth interior such as the one just described, pressure adjustments take place readily

1 Chree, C., Encyclopadia Britannica, Eleventh Edition, v. 8, pp. 813-816.

2 Nippoldi, A., Miuller-Pouillets Lehrbuch der Physik, 1914, pp. 1458-1459; Met. Zs., Braunschweig, 28, 1911, pp. 244-261.

- Among others may be cited the following: JAHR, E, Untersuchungs Ergebnisse uber den naturlichen elektrischen Erdstrom, Elektrot. Zs., Berlin. v. 23, 1902, pp. 196-197; BRUNHEs, B., Sur les courants telluriques, Paris. C.-R. A cad. Sci., v. 151. Aug. 1, 1910, pp. 409-411. 
under the action of gravity, provided the soil is not too moist. It was found that the E. M. F. between the two ends of the tube showed a component which reversed its direction when the tube was inverted, and which, if acting alone, would cause the lower end of the tube to function as its cathode. The E M. F.'s were measured by means of a balance method, readings being taken at intervals of about two minutes, which was the time required for inverting the tube, securing a balance, and recording the result.

Table 1 gives the results of a set of such observations, the same electrode, designated as $A$, being positive throughout:

Table 1.

\begin{tabular}{c|c|c}
\hline Time & Position of $A$ & E. M. F. \\
\hline \multirow{2}{*}{$\begin{array}{l}\text { m } \\
930\end{array}$} & & Uolt \\
& Up & 0.028 \\
& Down & 0.077 \\
& Up & 0.038 \\
& Down & 0.045 \\
945 & Up & 0.006 \\
& Down & 0.036 \\
& Up & 0.033 \\
\hline
\end{tabular}

This gives a mean of 0.053 volt for the total $E$. M. F. when the positive end is down, and 0.026 volt when the positive end is up, which corresponds to a mean value of 0.014 volt for a component of the E. M. F. having a reversible direction relative to the tube, or, in other words, a constant direction relative to the difference of pressure between the two electrodes.

Experiments were made with several other tubes and with various pairs of electrodes, but always with results similar to the above. As was to be expected, the mean value of the reversible effect for a set of readings, depending as it did upon various factors, did not remain constant from day to day, even for the same length electrodes. These mean values ranged for different conditions from 1 to 23 millivolts in tubes about $150 \mathrm{~cm}$ long, although most of them were between 10 and 15 millivolts. Only when the soil was too dry, or when it was too wet to flow properly, was there any absence of consistent results Occasionally the non-reversible component of the E. M. F. was smaller than the reversible component, in which case the total observed E M. F. consistently

- Drs Coudres, Ann. Physik, Leiprig, v. 55, 1895, p. 213. 
showed its cathode to be at the lower plate. This, however, was not usually the case with tubes containing soil only, and is not to be regarded as typical.

In general, the reversible E. M. F. increased with the degree of moisture so long as the soil was not too moist for successful operation. All the tubes showed used considerable variations in total E. M. F. with variations in the difference between the temperatures at the two electrodes. This variation was always such that the electrode whose temperature was increasing relative to the other tended also to become positive with regard to the other.

Materially increasing the length of the tube in order to observe directly the effect of increased pressure difference was not feasible because of the attendant increase in operating difficulties. In order, however, to obtain some evidence along this line the plan was adopted of employing a much stronger and somewhat larget tube in which an increased difference of pressure could be secured by the insertion of a heavy brass cylinder midway between the electrodes Observations made with and without the cylinder are, of course, not strictly comparable. This is partly due to the impossibility of reproducing the initial conditions at the main electrodes after introducing the cylinder and partly to the possible introduction of differential effects at the upper and lower faces of the cylinder. While it is not possible to separate these component effects, it is interesting to note that in both cases (using different cylinders) where this procedure was followed there was such a large increase in the reversible component of the total E. M. F. that the lower electrode was always positive, regardless of which end of the tube was at the bottom. The data in Table 2 were obtained by using a bituminized fiber tube of $150 \mathrm{~cm}$. length and $7 \mathrm{~cm}$. inside diameter. The electrodes were zinc cylinders $6 \mathrm{~cm}$. in length and $3.5 \mathrm{~cm}$ high. Each electrode had its surface cleaned by filing, and was imbedded in the soil about $15 \mathrm{~cm}$. from one of the ends. The brass cylinder used was $35 \mathrm{~cm}$. long and $6 \mathrm{~cm}$. in diameter. The soil had been sifted to secure uniformity of composition and moisture.

Before the introduction of the cylinder the end $A$ remained positive throughout, and the mean reversible component was only 0003 volt; after the cylinder was introduced the lower end was always positive, and the mean reversible component was 0.102 volt. Experiments were made on the following day, using a different cylinder, gave similar results. It appears probable, therefore, 
that an increase in pressure difference is accompanied by an increase in the associated E. M. F., although the data obtained are inadequate for the determination of the connecting relation.

Table 2.

\begin{tabular}{|c|c|c|c|c|}
\hline Time & End down & End positive & E. M. F. & Remarks \\
\hline $\begin{array}{cc}h & m \\
14 & 43 \\
& 45 \\
& 47 \\
& 48 \\
& 48 \\
& 50 \\
& 51 \\
15 & 53 \\
& 55 \\
16 & 16 \\
& 18 \\
& 21\end{array}$ & $\begin{array}{l}\text { A } \\
\text { B } \\
\text { A } \\
\text { B } \\
\text { A } \\
\text { B } \\
\text { A } \\
\text { B } \\
\text { A } \\
\text { B } \\
\text { A }\end{array}$ & $\begin{array}{l}\text { A } \\
\text { A } \\
\text { A } \\
\text { A } \\
\text { A } \\
\text { A } \\
\text { A } \\
\text { A } \\
\text { A } \\
\text { A } \\
\text { A }\end{array}$ & $\begin{array}{c}\text { volt } \\
0.0210 \\
.0180 \\
.0375 \\
.0300 \\
.0390 \\
.0315 \\
.0360 \\
.0300 \\
.0375 \\
.0300 \\
.0360\end{array}$ & 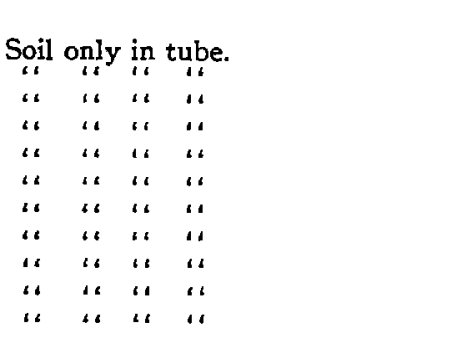 \\
\hline $\begin{array}{l}30 \\
32 \\
36 \\
38 \\
40\end{array}$ & $\begin{array}{l}\text { A } \\
\text { B } \\
\text { A } \\
\text { B } \\
\text { A }\end{array}$ & $\begin{array}{l}\text { A } \\
\text { B } \\
\text { A } \\
\text { B } \\
\text { A }\end{array}$ & $\begin{array}{l}.0750 \\
.1500 \\
.0068 \\
.1650 \\
.0600\end{array}$ & 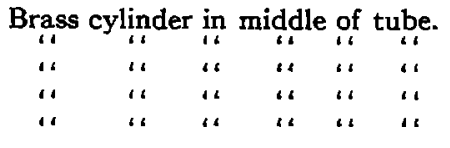 \\
\hline
\end{tabular}

In addition to the experiments with earth-filled tubes, some measurements were also made on tubes filled with salt water. For the salt-water solutions the observed values of the reversible E. M. F., based on readings taken immediately after inversion, are in good agreement with those obtained by Des Coudres.

\section{Conclusions (Part I).}

It has been shown that in a cell consisting of a non-conducting vertical tube filled with moist soil and supplied with a metal electrode near each end, there exists a component of the total E. M. F. whose direction tends to establish a cathode at the lower electrode regardless of the orientation of the tube; i. e., the electrode under greater pressure tends always to be positive with regard to the other one.

The magnitude of the effect varied with the nature of the electrodes and soil, but was always much in excess of the effects observed in simple salt solutions by Des Coudres. It is probable that the theoretical basis in the present case is not the same as that investigated by him. 
Apparently the E. M. F. associated with difference of pressure at the electrodes increases with increased pressure-difference, although the law of variation is not known.

From the standpoint of earth-current measurements the important features to be noted are as follows:

1. If the effect observed is representative of a general pressureeffect, it is of the order of magnitude necessary to account for the potential differences which have been found by various observers to be associated with vertical earth-currents.

2. The electrode at greater depth would by the operation of this effect tend to be permanently positive toward the upper one This is in agreement with many recorded observations.

3. It is obvious that such an effect could not give rise to annual and diurnal variations. It is of interest in this connection to note that some observers have commented on the constancy of the vertical earth-currents which they observed, while others have called attention to the smallness of the diurnal variation of such currents.

Part II.-OUt-of-Door Experiments on the Relation Between Temperature Difference and Plate E. M. F. for a Given Pair of Earth-Plates, and Its BEARING ON MEASUREMENTS OF THE VERTICAI EARTH-CURRENT

As indicated in Part I, the electrodes used in the laboratory experiments for investigating the effect of pressure difference at the electrodes showed that a marked relation existed between temperature difference and E M. F. It was decided to study this relation under conditions of temperature and moisture such as hold in actual earth-current measurements. The general plan was to secure, by means of automatic recording devices, continuous records showing the simultaneous variations in temperature difference and E. M F between two earth-plates buried at different depths. In order to secure a rather large variation in temperature difference, one of the plates was buried near the surface, where both the diurnal and seasonal changes are large, and the other in the same vertical line, but at a depth corresponding to relatively small temperature fluctuations. The influence of natural earthcurrents and industrial strays upon the recorded E. M. F. was eliminated by enclosing both these plates in a vertical cylinder of insulating material. For comparison purposes, continuous records 
were also obtained showing the variation in potential difference between a second pair of plates similar to the first and similarly located, except that they were outside of the insulating cylinder containing the other circuit. The two vertical circuits were located about $6 \mathrm{ft}$. west of Observing House $A$ of the Department of Terrestrial Magnetism, at Washington, in order that this structure could be used as a shelter for the recording and calibrating systems.

Owing to the great variations of temperature to which all the apparatus was necessarily subjected, measurements of great precision would have been difficult to obtain, had they been desirable. Since the results of refined and highly accurate measurements would in this case serve no useful end, being strictly applicable to the present installation only, the choice of apparatus and method was made with a view to securing only such a degree of accuracy as would be generally useful in the consideration of earth-current measurements.

The general arrangement of the underground systems is shown in Fig. 1. $E_{1}$ and $E_{2}$ are zinc earth-plates forming the electrodes of the insulated circuit, $P_{1}$ and $P_{2}$ the electrodes of the non-insulated comparison circuit, and $T_{1}$ and $T_{2}$ platinum resistance-thermometers located midway between the two upper and the two lower electrodes, respectively. The two circuits were about $45 \mathrm{~cm}$ apart.

The insulating tube was made by filling with molten pitch the annular space between two strong coaxial pasteboard cylinders. The inner and outer surfaces of the tube were also covered with an application of hot pitch. The lead wire from $E_{2}$ was carried up to the surface between the two pasteboard cylinders. The length of the tube was $225 \mathrm{~cm}$., and its average inside diameter was 20 $\mathrm{cm}$ The average thickness of pitch between the pasteboard cylinders was $2 \mathrm{~cm}$. The insulation provided by this tube proved to be entirely satisfactory throughout the period of its use. ${ }^{5}$ The tube as installed projected about $10 \mathrm{~cm}$. above the surface of the ground, the level of which was the same in the tube as outside. $E_{1}$ was $25 \mathrm{~cm}$ below the surface, and $E_{2}$ about $10 \mathrm{~cm}$. from the lower end of the tube. At the time of installation the distance

\footnotetext{
- For two months prior to the installation of the tube described above, the plates $E_{1}$ and $E_{2}$ were inclosed in a pitch-coated tube of bituminized fiber $210 \mathrm{~cm}$. Iong and $7 \mathrm{~cm}$. inside diameter. This tube provided fair insulation, but owing to its small cross-section, the resistance of the insulated circuit was so high as to prevent its recording system from being operated at the desired sensitivity. With the new tube, installed in November, 1916, ample sensitivity was never lacking. The change to the new tube was not accompanied by any appreciable change in the phenomenon under observation.
} 
between the level of the upper and lower electrodes was $180 \mathrm{~cm}$. for each circuit.

All the leads consisted of suitable copper wires covered with a high-grade of water-proof insulation, which had been subjected to a thorough under-water test.

All the soil excavated in connection with the installation of the underground systems was of rather uniform composition, consisting of clay with a considerable admixture of finely-divided mica. On its replacement, the soil was well tamped, care being taken to have the greatest possible uniformity in the soil surrounding the four electrodes.

Inasmuch as no drainage could be provided for the tube, it was desirable that this should receive much less rain than the surrounding soil. A ventilated hood was therefore used to protect it from excessive rain and snow, although an attempt was made to counteract the effect of evaporation by occasionally allowing the tube to remain uncovered during a shower. During fair weather the tube was not covered, in order to secure a fair degree of uniformity in regard to insulation and evaporation at the surface of the soil above the two circuits. The effect of unequal moisture conditions in the two circuits will be again referred to in the discussion of results.

The platinum thermometers $T_{1}$ and $T_{2}$ had a fundamental interval of about $1.5 \mathrm{ohm}$ each. They were inclosed in thin-walled glass tubes, which in turn were protected by rather closely-fitting brass tubes provided with water-tight sealing chambers for introducing the leads. Precautions were taken to have the thermometer tubes free from moisture before they were sealed into the brass tube, in order to prevent condensation effects during periods of low temperature. The thermometers were provided with compensating leads and used in connection with a manganin bridge of Callendar and Griffith's pattern, each thermometer being in series with the compensating leads of the other. The system was calibrated to give temperature differences directly, $15 \mathrm{~mm}$. on the bridge wire corresponding to a temperature difference of $1^{\circ} .0 \mathrm{C}$. While this limited the determination of daily base-values to an accuracy of about $0^{\circ} .01 \mathrm{C}$., departures from these base values, resulting from the dirunal variation, would have been obtainable to a much greater precision had they been desired. For our present purpose, however, we are mostly concerned with relative values throughout the day, and since the photographic records were only 


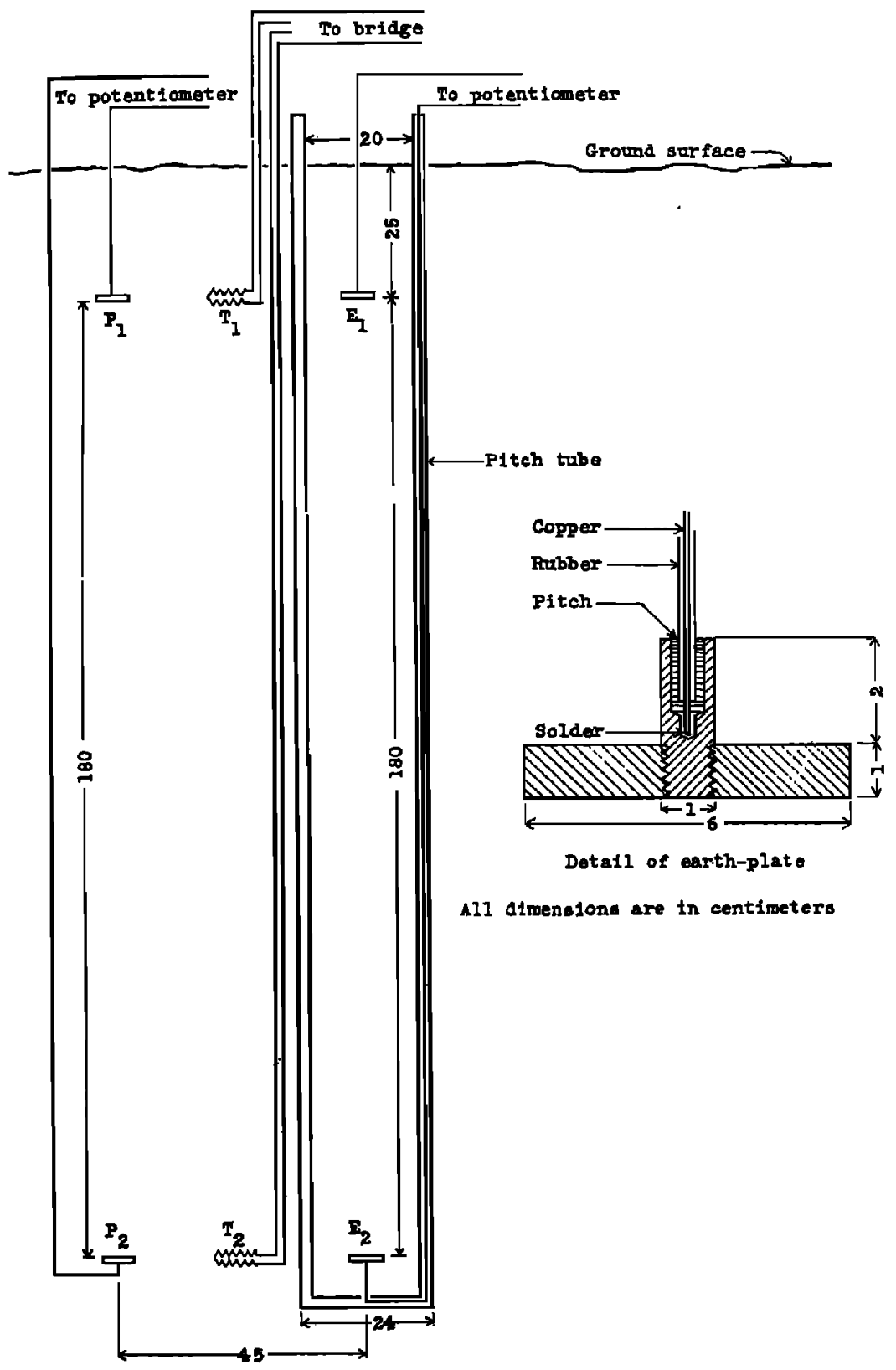

FIG. 1. 
$19 \mathrm{~cm}$. in width, while the change in temperature difference was sometimes as great as 2 or 3 degrees during 24 hours, it is obvious that a high sensitivity was undesirable. The average sensitivity employed was such that a change of $1^{\circ} .0 \mathrm{C}$. in temperature difference corresponded to a $50 \mathrm{~mm}$. change in deflection on the photographic record. While it was nearly always possible, in scaling values from the traces, to determine departures from the base value with an accuracy of about $0^{\circ} 002 \mathrm{C}$., these values were rounded off to the nearest $0^{\circ} .01$ for recording.

In the preparation of the earth-plates the aim was to secure as great a similarity as possible between the corresponding electrodes of the two circuits to facilitate comparison of results. The two upper electrodes $E_{1}$ and $P_{1}$ were formed from the two halves of a zinc cylinder about $3 \mathrm{~cm}$. high and $6.5 \mathrm{~cm}$. diameter, while $E_{2}$ and $P_{2}$ were similarly obtained from a second cylinder of the same dimensions. Each of the plates was turned to size and provided with a special tube enclosing the connection to its lead, as shown in the detail of Fig. 1. Considerable care was taken to have uniformity of process and of heat treatment while making the solder joints between the copper wires and the zinc connecting tubes. One end of each of the four copper leads was bared and carefully tinned, the rubber insulation being wrapped with a wet cloth during the operation. A small amount of soft solder and a bit of rosin was dropped into the receptacle indicated in Fig. 1, after which the connecting tube was carefully heated on a hot metal plate. As soon as the solder was melted, the tinned end of one of the wires was introduced into it and the connecting tube cooled in water to prevent unnecessary heating of the insulation. The space between the rubber insulation and the surrounding tube was filled with pitch, the metal tube being set in a shallow pan of boiling water until the pitch was all melted. Usually pitch had to be added several times before the tube was filled. After cleaning the surfaces of the connecting tube and electrode, the parts were assembled and amalgamated.

The leads associated with each of the earth-plate circuits were connected to one of two high-resistance potentiometers, one lead passing directly to the potentiometer and the other making its connection through a sensitive moving-coil galvanometer. The advantage of using potentiometers for these measurements is apparent when one considers the question of polarization of the earth-plates. With potentiometers adjusted for balance there 
would of course be no polarization; further, with a base-value approximately equal to the mean potential difference (P. D.) for the day, the current in a given circuit would be very near zero for much of the time, and would in general reverse its direction several times during the day. There was in fact at no time any evidence of polarization in either circuit.

Continuous records were obtained by the photographic method, using a recording drum driven by clockwork. The record sheets were $19 \mathrm{~cm}$. wide and $40 \mathrm{~cm}$ long, all three traces for a given day being recorded on a single sheet. As already stated, it was found necessary to limit the recording sensitivity of the thermometer system to about $0^{\circ} .02$ per $\mathrm{mm}$. to keep the spot of light on the recording sheet. For like reason the average recording sensitivity of the other two systems was about $5 \times 10^{-5}$ volt per $\mathrm{mm} .^{6}$ The base values for each of the earth-plate systems could be determined with an accuracy of $1.0 \times 10^{-4}$ volt.

Time indications and base lines were obtained hourly by shortcircuiting the terminals of each galvanometer. This was effected by means of a clock arranged to operate mercury-contact shunts. Frequent tests showed that with proper care no spurious effects of appreciable magnitude were introduced by this procedure. It was adequate for the purpose of the work in hand to obtain from the traces, at intervals of one hour, the approximately simultaneous values of the elements under observation. The possibility of errors due to wandering of galvanometer zeros was eliminated by scaling the hourly values corresponding to the time of the hourly zero record. Base values were adjusted.and sensitivities determined daily.

The observations were continued without serious interruption from September, 1916, to May, 1917. During the winter months the temperature variations were naturally very irregular and not well suited for automatic registration, because of the great extremes which caused frequent departures of one or more of the recording spots from the photographic record. It was considered worth while, however, to continue the registration to obtain data regarding certain conditions which are peculiar to the season, as, for example, the effect of a layer of snow over the soil and the effect of frozen soil at the upper electrode. When observations were begun in September and again when they were discontinued in

- The accuracy attainable in scaling the P. D. traces was about $1.0 \times 10^{-1}$ volt for the insulated circuit, and $1.0 \times 10^{-1}$ volt for the other one. In both cases the values were tabulated to the nearest 0.0001 volt. 
May, the temperature at the upper thermometer was several degrees higher than at the lower one, while the extreme reverse condition was reached on February 13, 1917, when the temperature at the lower thermometer was in excess by $14^{\circ} .6 \mathrm{C}$. These figures give an idea of the seasonal variations upon which the observed diurnal variations were superposed. During the winter there was, as stated above, no regular diurnal variation, the temperature difference sometimes remaining almost constant for days, when the ground was covered with snow, and at other times, in the absence of snow, undergoing large but irregular fluctuations. Because of their opposed seasonal variations and because of their similarity in all other respects, the autumn and spring values only were used in the preparation of the mean diurnal-variation curves shown in Fig. 2. Results were included only from those days on which the records were complete for all three elements or could be made complete by a small amount of justifiable interpolation. On this basis of selection the number of days available for computation of the mean hourly values represented in Fig. 2 was limited to 87 .

Curves $A, B$, and $C$, of Fig. 2 represent, respectively, temperature at upper thermometer minus the temperature at lower thermometer, P. D. between the terminals $E_{1}$ and $E_{2}$ of the insulated circuit, $E_{1}$ being positive, and P. D. between the terminals $P_{1}$ and $P_{2}$ of the non-insulated comparison circuit, $P_{1}$ being positive. During the last two months of the observation period, unfortunately some errors were introduced into the temperaturedifference records, due to a short piece of iron pipe which had been driven into the soil not very far from the upper thermometer for the purpose of making some auxiliary measurements with a mercury thermometer. Comparison of the curves obtained with this pipe in position with similar curves obtained in absence of the pipe showed that its effect was negligible except during the hours of intense sunshine. Further, the curve representing the mean hourly values of the air temperature in Observing House $A$, obtained from thermograph records, is everywhere similar to curve $A$ (if we take account of the difference in phase), except between the hours of 8 and 16. The dotted portion of curve $A$, therefore, was drawn in conformity with the shape of the mean air-temperature curve, taking account of lag, and the mean temperature-difference curve for days when the disturbing pipe was not in position.

From a comparison of curves $A$ and $B$ of Fig. 2 we see that 
for the insulated circuit there was a very close agreement between the variations in temperature difference and $P$. D., and that a change of $1^{\circ} .0 \mathrm{C}$. in temperature difference was accompanied, on the average, by a change of about 1 millivolt in P. D. It is seen also that the direction of the effect is such that increasing the temperature of the upper plate with regard to the lower one causes

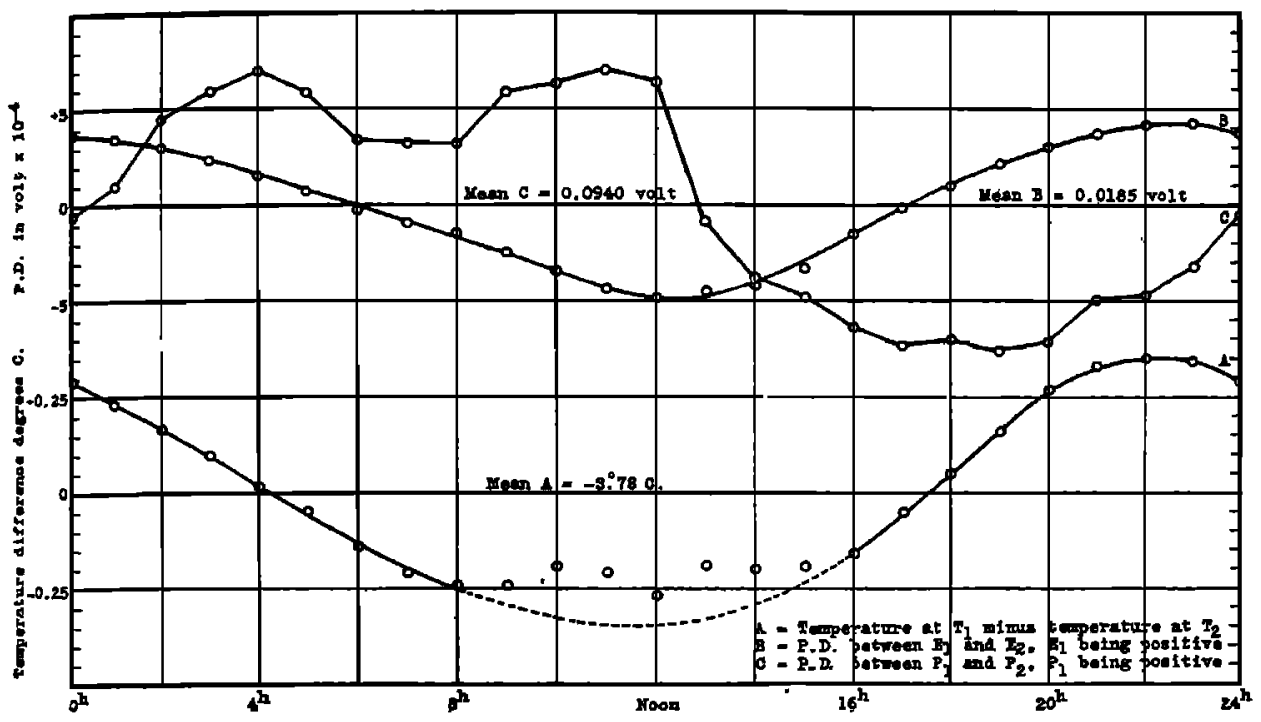

FIG. 2.

the upper plate to become increasingly positive with regard to the lower one This is in agreement with the qualitative results obtained in the laboratory and referred to in Part I. Curve C of Fig. 2, on the other hand, has an amplitude twice as large as that of $B$, and shows no similarity to curves $A$ or $B$, unless one assumes a very large difference in phase. We evidently cannot look to the thermal effect which is so obvious in curve $B$, to explain curve $C$. It should be stated that in one respect the records for the two earth-plate circuits always showed a marked difference, the trace represented by $B$ being always a relatively smooth curve, while that represented by $C$ was never free from small fluctuations, except between the hours of 2 and 5. Inasmuch as most of the electric-railway lines in the District of Columbia are not grounded, and since the line of the Chevy Chase Electric Railway, only 0.5 mile ( 800 meters) distant, is one of the few outlying lines using 
the track as a return, it was thought that a study of the load conditions prevailing on this line might be instructive. Through the kindness of the officials of the Capital Traction Company, it was possible to obtain access to the records of the desired data. Curve $A$, Fig. 3 , shows the mean value of the railway's load in amperes for each hour of the day, over a period of 14 days. Curve $B$ corresponds to the mean hourly values of the P. D. between $P_{1}$ and $P_{2}$ for the same 14 days. While consistent mean curves cannot be expected from so short a period as 14 days, the two curves do nevertheless show evidence of a very close relation. Curve $C$ of Fig. 3 is the same as Curve $C$ of Fig. 2, namely, the 87-day mean curve for P. D. between $P_{1}$ and $P_{2}$. If this curve were corrected for temperature effects and plotted against the corresponding 87-day mean load curve, we would probably find most if not all of its diurnal variation accounted for. Although the railway data are not now in hand for making such a comparison, the conclusion seems warranted, nevertheless, that nearly all of the observed diurnal variation between the two earth-plates $P_{1}$ and $P_{\mathrm{a}}$ was due to variations in temperature difference and to stray currents from the nearby electric railway.

All the observations suitable for discussion divide themselves naturally into two groups, namely, those in which the temperature at the upper thermometer was above $-1^{\circ} .0 \mathrm{C}$. and those for which

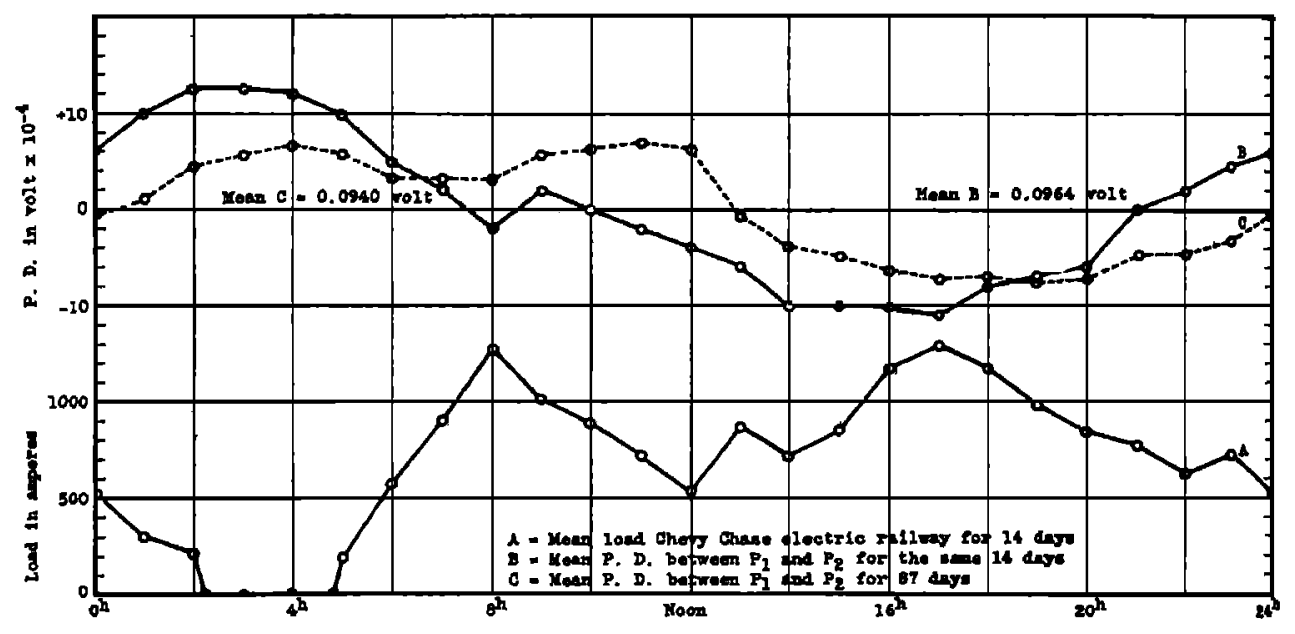

FIG. 3. 
it was below $-2^{\circ} .0 \mathrm{C}$. All the curves thus far shown belong to the first class.

During most of February, 1917, there was little or no snow on the ground where the observations were carried out. At a temperature of somewhere between $-1^{\circ} .0$ and $-2^{\circ} .0 \mathrm{C}$. the soil at the upper electrode became frozen and remained in this condi-

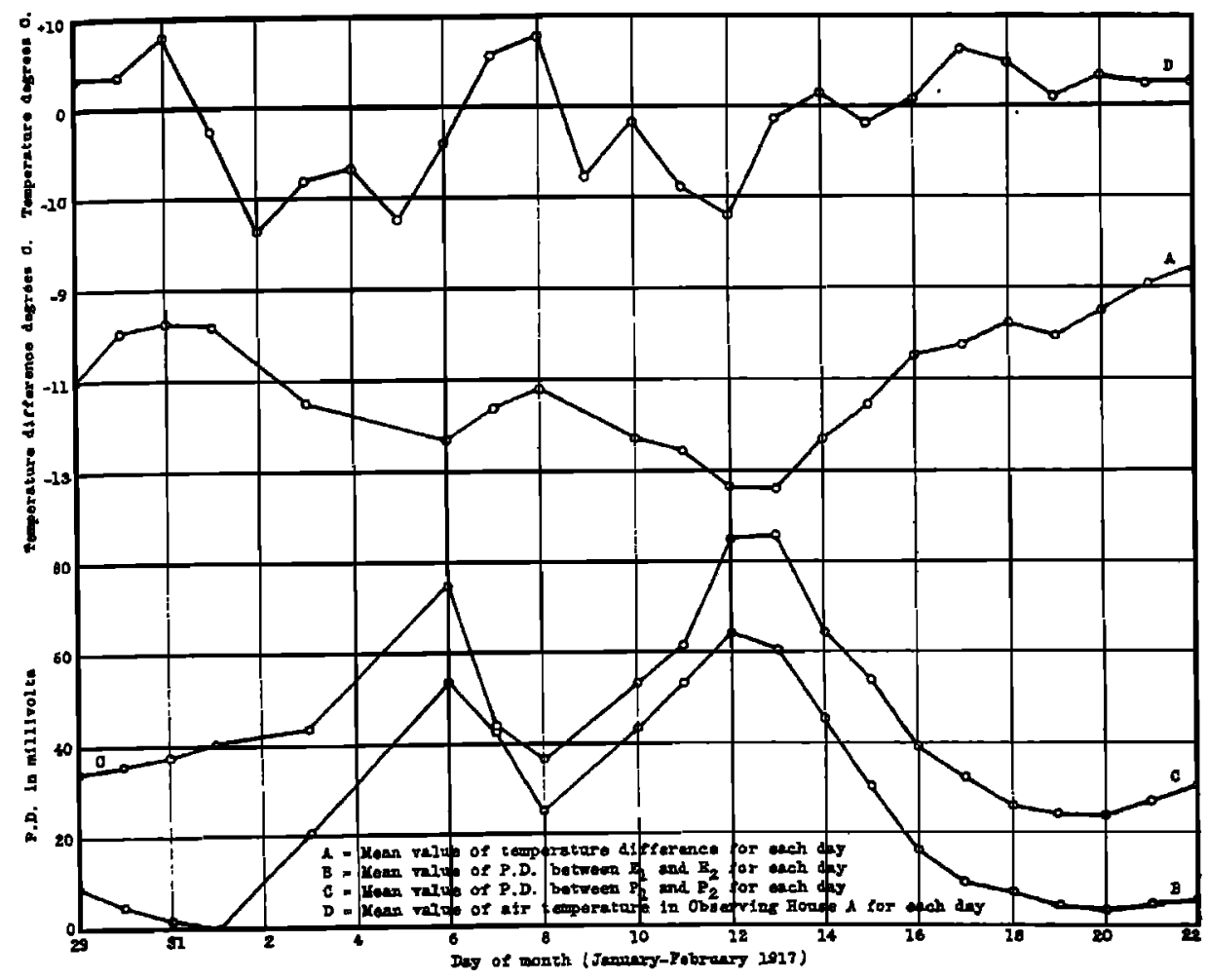

FIG. 4.

tion for several weeks. Throughout the period during which the temperature at the upper thermometer was below $-2^{\circ} .0 \mathrm{C}$. the temperature effect was between 15 and 20 times as large as that found to prevail in autumn and spring. Furthermore, the sign of the effect was reversed. In other words, before January 25 and after February 25 a $1^{\circ} .0$ increase of temperature at the upper electrodes relative to the lower ones was accompanied by an increase of 1 millivolt in P. D., the upper plates becoming more 
positive with regard to the lower ones; while between February 1 and 19 a relative temperature increase of $1^{\circ} .0$ at the upper electrodes corresponded to a decrease of 15 to 20 millivolts in P. D., the upper plates becoming relatively less positive. The pronounced difference between the two cases is well shown by a comparison of Figs. 4 and 5. In Fig. 4 we have for each of the elements the mean values for each day (except for several days when records were incomplete), for the period January 29 to February 22, 1917, the system used in plotting being the same for Figs. 4 and 5 as was used in Figs. 2 and 3. A glance at the curves shows that the $\mathrm{P}$. D. curves $B$ and $C$, corresponding to the insulated and noninsulated circuits, respectively, are here very similar and run parallel courses, but are both opposed in curvature to the corresponding temperature-difference curve $A$. These characteristics were as clearly marked on the daily traces as in the means here shown. The reason for similarity between $B$ and $C$ on daily traces for this period is of course the fact that the amplitude of the total P. D. changes was so great that the effect of electric-railway strays was small in comparison. It has been stated that a change of $1^{\circ} .0$ in temperature difference corresponded under the present conditions to a change of 15 to 20 millivolts. This relation is substantially the same whether obtained from the continuous record for a single day or from the mean values corresponding to individual days as given in Fig. 4. Curve $D$, representing the mean air temperature in Observing House $A$, for the period corresponding to the other curves, is added to show the relation between the atmospheric temperature changes and the other elements under consideration.

The possibility of any appreciable part of the effects just described having been due to temperature effects on the LeClanche cells associated with the potentiometers was investigated in the laboratory at the conclusion of the out-of-door observations. The E. M. F. of each of the cells was carefully compared with that of a Weston standard cell maintained at constant temperature, while its own temperature was carried several times over the entire range to which it had been subjected during the course of the outside work. It was found that the total variation in E. M. F. corresponding to the temperature range from $+35^{\circ} \mathrm{C}$. to $-16^{\circ} .5 \mathrm{C}$. was an increase of $1 \%$ for one cell and a decrease of $1.4 \%$ for the other. It is true that most of the variations in E. M. F. corresponded to the lower temperature, but it is interesting in this con- 
nection to note that the temperature coefficients for the two cells were of opposite sign while the phenomena observed in the two earth-plate circuits were of like sign. The significant thing, however, is that, regardless of sign, the temperature effects in the potentiometer cells could account for only about $1 \%$ of the actual E. M. F. variations which were observed in the earth-plate circuits.

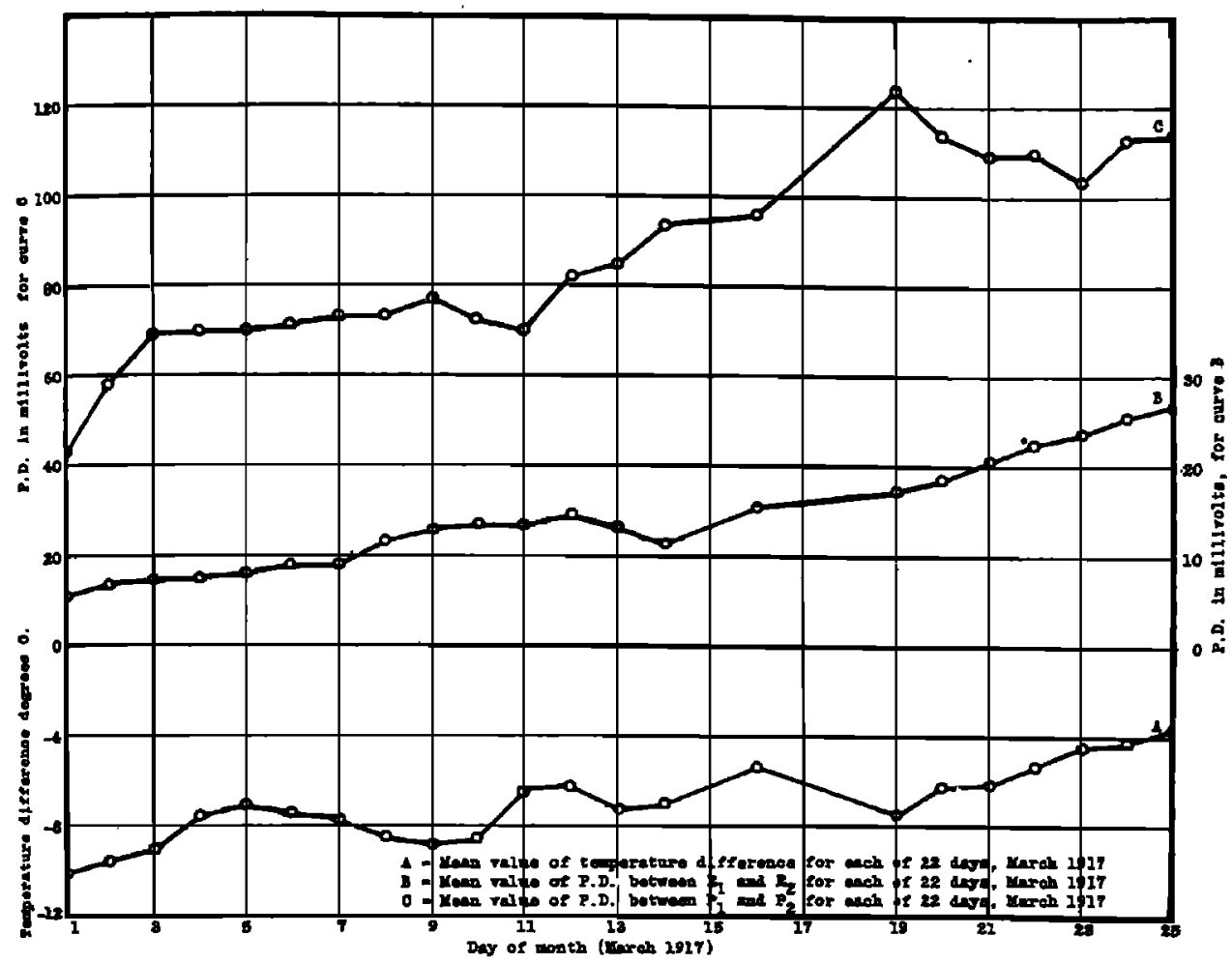

Fig. 5.

During the period between February 20 and March 1 the temperature at the upper electrodes was very unsteady, apparently passing several times through a critical value. After March 1, however, it never went below $-1^{\circ} .0$, and advanced rapidly with the season. The curves of Fig. 5 represent the progressive change of the three elements from March 1 to March 25, 1917. It is obvious that the mean values for each day cannot show as well defined a parallelism between the curves as would be seen from the hourly 
values for a single day, or, better still, the mean hourly values of several days. However, the general parallelism of the curves in Fig 5 is in marked contrast to the opposed curvatures between the P. D. curves and the temperature-difference curve of Fig. 4. Not only was the sign of the temperature effect after March 1 again as it had been before January 25 , but the relation between change of temperature difference and change of $\mathrm{P}$. D. was again practically as before.

As a matter of fact, the lack of parallelism in Fig. 5 is due mainly to the effects of unequal moisture conditions in the two circuits. As previously stated, it was not possible to maintain identical conditions for the two circuits in this respect. In general, it was found that for equal changes in temperature difference the corresponding change in $P . D$. increased somewhat with the degree of moisture. For example, for two months before the beginning of the autumn rains, when the soil was very dry, the mean change in P. D. per degree change in temperature difference was about ten per cent lower than the mean of all days, while during winter and early spring it was about ten per cent above the mean. In addition to this effect of moisture on the relation between temperature difference and P. D., however, there were large effects directly resulting from moisture changes, which were observable even in the absence of variations in the temperature difference. It is this effect which was responsible for the difference between the average daily changes in P. D. for the two circuits during March.

\section{Conclusions (Part 2).}

1. The results given above, while strictly applicable only to the present installation, show the general nature and the order of magnitude of the effects to be expected when two earth-plates are subjected to a variable difference of temperature.

2. It appears that the natural plate E. M. F. between two electrodes buried at different depths in the same vertical may, on account of changes in their temperature difference, have a diurnal variation as large as that which has been ascribed by some observers to a true vertical earth-current. The diurnal variations observed by Brunhes (l. c.) at the Messeix mines certainly seem to be explainable on this basis.

3. Such effects as the observed prevailing tendency of earthcurrents to flow from the foot of a mountain to its summit, and the 
marked relation between the activity of a volcano and the direction of current flowing up or down its sides, must certainly be considerably influenced by the effects of temperature difference on the plate E. M. F., and may perhaps not be as completely controlled by atmospheric-electric phenomena as has sometimes been supposed.

4. It is evident that care should be taken to have earth-plates buried well below the frost level of the soil. This would apply with especial force to plates located on mountain summits, or where it is desired for special reasons to limit the depth.

5. Since the average diurnal variation for horizontal earthcurrents as deduced from the results of measurements on lines not more than several kilometers in length is of the order of 0.001 volt $/ \mathrm{km}$. per hour, it is obvious that adequate provision should be made either for eliminating or taking account of temperaturedifference effects. This would especially be the case with measurements made at different depths to determine the variation of earth-current density with depth.

6. It has long been recognized that non-polarizable electrodes are desirable for earth-current measurements. Such an electrode usually consists of a zinc or copper plate immersed in a solution of zinc sulphate or of copper sulphate, respectively, contained in a porous earthen vessel. When it is considered, however, that

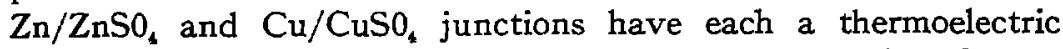
power of nearly a millivolt per degree, it would seem that the use of such electrodes is not, for short earth-current lines, a sufficient precaution for ensuring reliability of results, unless one can also be sure that temperature differences are negligible.

7. The importance of controlling spurious variations in earthcurrent measurements lies, of course, in the fact that most of the definite knowledge which we can hope to secure concerning earthcurrents, must come from a study of their variations. This is especially true where the interrelations between earth-currents and terrestrial magnetism are concerned.

Department of Terrestrial Magnetism, Carnegie Institution OF Washington. 